\title{
Observatorio dos videoxogos galegos: proposta pedagóxica sobre xogos dixitais e ludificación educativa
}

\author{
Silvia López \\ Facultade de Ciencias da Educación, Universidade de Santiago de Compostela
}

\begin{abstract}
Resumo
O obxectivo deste traballo é presentar unha proposta xurdida dunha tese de doutoramento iniciada no curso académico 2013/2014 dentro do Programa de Doutoramento en Educación da Universidade de Santiago de Compostela. Na proposta, denominada "Observatorio dos videoxogos Galegos", preténdese principalmente compilar, describir e analizar os xogos dixitais desenvolvidos na Galiza. Ademais neste documento, reúnense os principais videoxogos e empresas do sector, aportando elementos para a reflexión sobre o uso destes recursos como materiais educativos nos colexios.

Palabras chave: videoxogos, educación, cultura, ludificación.
\end{abstract}

\section{Introdución}

Nos últimos anos, os estudos sobre tendencias do futuro da educación apuntan á necesidade dunha redefinición da profesión docente (Gros, 2014). O profesor ten que sumir o rol dun guía que oriente ao alumnado no desenvolvemento de proxectos $\mathrm{e}$ actividades atractivas apoiadas en ferramentas tecnolóxicas. Profesorado e expertos coinciden en que antes de 2017 xeneralizarase a introdución dos dispositivos tecnolóxicos básicos na educación (Educación 3.0, xuño de 2015).

Se ben nos centros educativos galegos comezouse a introducir co proxecto ABALAR equipamentos informáticos, tentando rematar coa $1^{\mathrm{a}}$ fenda dixital relacionada coa acceso ás TIC e uso da Internet, queda moito que facer neste terreo e na formación didáctica en relación co uso destes recursos.

A este respecto tamén dende a Administración educativa semella que se fan esforzos por introducir no sistema recursos dixitais de diferente natureza, por exemplo máis de 2.300 alumnos/as de $5^{\circ}$ de Primaria de 84 centros iniciaron o curso 2014-2015 con libros dixitais e gratuítos no marco da iniciativa e-DIXGAL. Mais se leva anos creando actividades interactiva, videoxogos e outros contidos educativos en formato multimedia, así os primeiros videoxogos propiamente didácticos foron creados no país hai 20 anos.

No caso concreto dos videoxogos, estes contan cada vez máis cun maior respaldo por parte da investigación en innovación pedagóxica para a súa inserción na aula como ferramentas educativas; de feito, estamos a asistir a unha gran proliferación de estudos ao redor das múltiples vantaxes e beneficios que poden comportar para os procesos de ensino e aprendizaxe (Rubio, 2012).

Ante este marco evidénciase unha falta de estudos dedicados á recuperación, avaliación e divulgación dos videoxogos elaborados na Galiza, que alén diso poidan contribuír á mellora da práctica docente.

\section{Do CD-ROM educativo á ludificación educativa}

Nunca o profesorado tivo tantos medios á súa disposición como na actualidade, de maneira que xunto aos tradicionais materiais impresos, están a aparecer outros que amplían as posibilidades que estes poden desempeñar no ensino (Cabero e Romero, 2007). Dende a creación do CD-ROM a mediados da década dos 80 do século XX até hoxe, utilízanse pedagoxicamente blogs, wikis, titoriais, bases de datos, aplicacións de Realidade Aumentada, simuladores... e videoxogos.

Non caso dos videoxogos, existe un elevado número de teóricos da educación que sostén que os videoxogos comerciais ademais de ser un instrumento para o lecer poden converterse en ferramentas educativas para a aula.

A práctica de utilizar nas escolas estes medios tecnolóxicos fundaméntase teoricamente por unha banda, nas conclusións de estudos que evidencian os beneficios do xogo (Piaget, 1961; Bruner, 1977; Vygotsky, 1979; Tonucci, 2004; Marín, Penón y Martínez, 2008; Ôfele, 2015; entre outros). E por outra, nas investigacións e marcos de referencia centrados na relación entre videoxogos e educación: Prenski (2001, 2006), Gros (2004, 2008), Montero (2010), Lacasa (2011), Revuelta y Esnaola (2013), entre outros. En xeral, destas análises teóricas determínase que os videoxogos resultan de utilidade para o proceso de aprendizaxe, de entre outras, polas seguintes razóns: implicación activa do alumnado; axudan a focalizar a atención, evitando distraccións na aprendizaxe; proporcionan prácticas en habilidades de resolución de problemas; motivan e retan ao alumnado a un maior esforzo; apoian o desenvolvemento de estratexias importantes para a aprendizaxe: resolución de problemas, razoamento deductivo, memorización...

Aínda que xeralmente tamén se manifestan dificultades na súa implementación: dificultades técnicas, carencia de tempo, falta de formación e inseguridades do profesorado, os contidos dos xogos non sempre responden a materias, entre outras (Gros, 2012).

Polo tanto, o profesorado adoita utilizar nas aulas videoxogos educativos (Gfk, 2012), os cales sobresaen por ser dos xogos dixitais máis criticados. A seguinte cita pon de manifesto a opinión dalgúns autores respecto diso:

"Uno de los principales problemas del uso de videojuegos educativos es que aquellos que están diseñados para enseñar, suelen tener un marcado 
carácter educativo, lo cual los diferencia significativamente de los videojuegos a los que los alumnos juegan en casa y que tanto les divierten (Padilla, Medina, Paderewski, Gutiérrez y López, 2014: en liña)".

Tamén comeza a ser frecuente atopar pola rede e en revistas de temática educativa, propostas didácticas centradas no concepto de ludificación ou gamificación. A idea principal destes proxectos de ludificación educativa é utilizar a mecánica e as técnicas dos xogos tales como os incentivos, a retroalimentación inmediata e as recompensas no deseño do escenario de aprendizaxe (Gros, 2014).

Entre os recursos dispoñibles de forma online para poder gamificar unha clase e continuar esta gamificación a distancia, cóntase cunha serie de ferramentas como Class Dojo (https:/www.classdojo.com/) e Schoology (https://www.schoology.com/home.php).

Sen embargo, a pesar de que a selección por parte dos docentes de materiais de calidade aumenta as posibilidades de éxito nos procesos de aprendizaxe que realicen os estudantes, a eficacia didáctica dun medio depende sobre todo da maneira na que se utiliza (Marqués, 2002). Así é que cómpre saber seleccionar, analizar e utilizar os xogos dixitais na aula para obter os beneficios pedagóxicos que estes aportan.

\section{A proposta: Observatorio dos Videoxogos Galegos}

Para liquidar parte das limitación nomeadas no anterior apartado e coa finalidade tamén de divulgar o patrimonio lúdico dixital galego, está a crearse o "Observatorio dos Videoxogos Galegos” (en adiante OVG).

Propostas similares, pero centradas basicamente na recompilación de xogos dixitais témolos no proxecto "MINIMAP" (http://minimap.jolasean.eu/) creado no País Vasco, o "Museo FX" (http://juegos.fxinteractive.com/fx/El_Museo_FX/juega gratis.html), o "Gamification - World Map" (http://www.gamificationworldmap.com/), o "Game Industry Map" (http://www.gameindustrymap.com/map.php) e o "gamedevmap" (http://www.gamedevmap.com/).

Pero as funcións do OVG serían diversas, ademais de compilar os videoxogos creados na Galiza, estes serían descritos e analizados dende un punto de vista pedagóxico. Reuniríase ademais información, novas de interese e resultados de estudos sobre videoxogos, ludificación e educación, así como experiencias didácticas realizadas na práctica.

Asesoraríase sobre asuntos relacionados cos xogos e recursos dixitais en xeral, creando un lugar de encontro onde resolver dúbidas e fornecer colaboracións entre os diversos axentes relacionados coas temáticas, fundamentalmente empresas, administración, docentes, alumnado e familias.

Estamos ante un proxecto ambicioso, que precisaría de fontes de financiamento para ser levado á práctica nas súas diversas manifestacións, así é que a primeira fase do proxecto realízase con cargo á tese que se está desenvolvendo, centrado nun espazo web onde se recompilan os videoxogos creados.
Para levar a cabo esta primeira fase do proxecto, estase a realizar un estudo documental previo que axude a identificar as empresas creadoras de videoxogos na Galiza e, polo tanto, dar así cos videoxogos elaborados até o momento.

Para determinar as empresas recórrese a catro tipos de fontes:

- Buscas realizadas pola autora na rede. A este respecto resultou de gran valor atopar o Libro Branco do Audiovisual Galego (Xunta de Galicia, 2005), xa que no seu Capítulo 5 realízase unha achega ao sector multimedia enumerando empresas e xogos dixitais realizados até o ano de publicación do mencionado libro.

- Informacións procedentes de persoas implicadas no sector do videoxogo como pode ser Marcus Fernández (redactor da sección de videoxogos do xornal dixital de novas tecnoloxías Código Cero)

- Informacións procedentes de asociacións como DEV (Asociación Española de Empresas Desarrolladoras de Videojuegos), EGANET (Empresas Galegas Adicadas a Internet e as Novas Tecnoloxías), Clúster TIC Galicia e AUIC (Asociación de usuarios de informática clásica).

- Informacións de persoas particulares ao longo da realización deste traballo, sobre todo a través das redes sociais e en xornadas ou congresos.

A medida que se obteñen datos das empresas e dos videoxogos, inclúense nun blog (até o momento de carácter privado) (Véxase Figura 1) para posteriormente ser descritos e analizados a partir dunha guía de avaliación elaborada especificamente para esta finalidade.

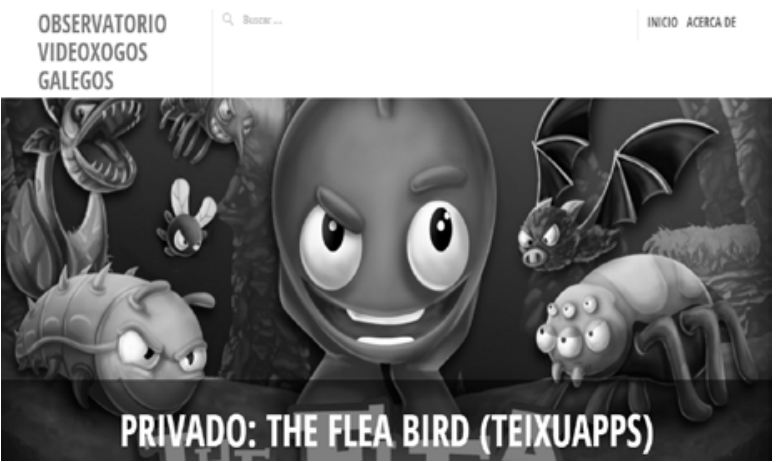

Figura 1: Captura parcial dunha das páxinas do OVG

\section{Os resultados: videoxogos galegos}

Neste aportado cítanse, sen ánimo de exhaustividade, algunhas empresas e videoxogos galegos. $\mathrm{Na}$ actualidade, estase en procesos de diálogo coas persoas implicadas na elaboración dos xogos para obter máis información.

Seguimos a Amoros e Fontán (2009) para coñecer as orixes e evolución da industria do videoxogo na Galiza até a primeira década do século XXI. Para estas autoras, as industrias multimedia galegas desenvolvéronse a raíz dunha serie de actuacións por parte da Administración 
autonómica: a posta en marcha en 1993 do Centro de Supercomputación de Galicia (CESGA), a creación da Rede de Ciencia e Tecnoloxía de Galicia (RECETGA) no 1995, e a creación en 1999 do Centro Multimedia de Galicia (CMG).

Sendo a primeira empresa galega en elaborar produtos multimedia de entretemento dixital a coruñesa Filloa Records (1994), selo que pertenceu a Dygra até o ano 2005. Entre os seus traballos cítanse: El Artista Virtual (1995), o xogo Bicho (1997), o simulador de maxia Quick Magic (1998) ou Escarnio (1998).

Outras empresas pioneiras son: Interacción (Vigo, 1997) cos xogos Pentagox (2002), a aventura gráfica El Templo (2004) e La arruga al poder (2011), e a empresa compostelá Imaxin Software (1997) encargada dos videoxogos $O$ misterio das sete pezas (2001), Lepi e o misterio do diario (2005), O avó de Paulo (2006), CLMNTK, the game (2008), ZooLoco (2009), entre outros.

A partir do ano 2000 xorden novas empresas multimedia galegas e con elas novos produtos dixitais e lúdicos: A aventura máxica de Merliño (Grupo de Investigación de Sistemas Informáticos de Nova Xeración da Universidade, 2001), Raspi en la granja (Novaimaxe Multimedia, 2001), O labirinto dos soños (Grándola Nova, 2002), Lixeiriño (Ozono Multimedia, 2003), entre outros.

No 2004, Martiño Figueroa desenvolven xunto co seu equipo e sen ningún tipo de apoio económico, un xogo de estratexia titulado Glest (culturagalega, decembro 2004).

E é que a falta de financiamento foi e segue sendo un detonante que afecta ao estudo e produción de videoxogos na Galiza, polo que algunhas empresas uníronse para colaborar ou crear novos estudos, como foi o caso da viguesa Alia 3D e Continental Games (departamento de videoxogos de Continental Producciones) aos que se lles atribúe o videoxogo E.L.E. (Evento Ligado a la Extinción). Posteriormente, no ano 2011, Alia 3D, Continental Games e Paralaxe (Spin off tecnolóxica da Universidade de Santiago de Compostela) crean xuntos unha nova empresa chamada Moonbite Games \& Animation (Fraga, marzo 2010), con sedes en Santiago de Compostela, Madrid e Barcelona. Entre os videoxogos destacados na páxina web da compañía se destacan: The Adventures of Papalux, E por que? e Zombeer.

Moonbite Games \& Animation é dos escasos desenvolvedores autorizados do mundo para Wii, PS3 e Xbox360 e ten a licenza de autopublicación nas súas tendas online (Méndez, 2011).

O primeiro xogo galego para iPhone foi Georain (publicado na AppStore o 2 de xullo do 2009), creado por Pablo Roca. Tratábase dun xogo de acción casual, onde se tiña que capturar cos dedos diversas figuras e levalas as súas correspondentes esquinas (Rodríguez, febreiro de 2010).

No terreo "indie" tamén destaca Pablo Soto que a través da súa compañía Soluciones Informáticas y Multimedia publica na App Store o xogo para iPhone e iPad Yoyago (Marcus, xaneiro de 2012).

Entre as empresas desaparecidas, pero sen dúbida gran referente na industria dos videoxogos galegos, foi a luguesa Small Wonders, co xogo de estratexia para iPhone Battle of Puppets no que o xogador tiña que conquistar un teatro rival (Suárez, xaneiro de 2010).

Tamén é destacable a Startup Teixuapps, que segundo Fernández, M. (comunicación persoal, abril do 2014) recupera xogos clásicos da época dos 8 bits como $\mathrm{La}$ Pulga.

$\mathrm{Na}$ actualidade, entre as empresas vixentes sobresaen: a nomeada Imaxin Software; Axóuxere Games (con xogos para Android e XBOX 360 como Trap Ball e Colours); Gato Salvaje (co videoxogo de aventura point and click $A R-K$ ); Ficción Games (a división produtora de videoxogos de Ficción Producciones, co videoxogo educativo Tutu e o advergaming A casa da Conexa); Ameiga (con War of Sides e The Stackers); Meiga Labs (con Corrupt Mayor Clicker e Time Pirates); Iberian Games (con Luchadores del Espacio, Kartoon Crazy Racing, Pursued e Colormania 2015).

Segundo o "Libro Blanco del Desarrollo Español de los Videojuegos" (DEV, maio de 2014), Galiza é a sexta comunidade autónoma por número de empresas produtoras de videoxogos en España.

\section{Conclusións}

Tomando como base os resultados obtidos a partir da revisión documental e tendo en mente o proxecto "Observatorio dos videoxogos galegos", extráense as seguintes conclusións xerais:

- $\mathrm{Na}$ Galiza non se está dando a coñecer a produción de videoxogos. Non se atopan sitios web que recollan os videoxogos realizados. Temos un patrimonio lúdico dixital de gran valor pedagóxico que se descoñece e, polo tanto, non se utiliza.

- É preciso contribuír á comunidade educativa con información sobre videoxogos e ludificación, que facilite a elección e utilización destes recursos para ser empregados nas aulas. O Informe Horizon 2014, no que se identifican e describen as tendencias chave nos procesos de ensino - aprendizaxe nos próximos cinco anos, destaca como tendencias a medio prazo a ludificación. Os videoxogos lideran os procesos de innovación en contornas educativas (Esnaola, De Ansó, García e Untref, 2014).

- As subvencións e financiamento para desenvolver videoxogos ou contidos interactivos é case inexistente. Esta situación está a levar aos produtores galegos de videoxogos a unir forzas nunha asociación que poida servir para darlles unha voz única e facilitar así unha interlocución directa coa Administración, coordinar accións e canalizar liñas de apoio (Fernández, xaneiro 2015)

- Un dato alarmante é que nesta investigación está sendo complexo conseguir ou obter información das empresas, dalgúns dos xogos dixitais desenvolvidos con axudas públicas. Por exemplo as concedidas pola Axencia Galega das Industrias Culturais (Agadic) no ano 2010. 


\section{Referencias}

Amoros, A. e Fontán, M. (2009). El Sector Multimedia en Galicia: Origen, situación $\mathrm{y}$ perspectivas. Observatorio (OBS*) Journal. 9, 254-266.

Bruner, J. (1977): The process of education. Cambridge. MA: Harvard University Press.

Cabero, J. e Romero, R. (Coord.) (2007). Diseño y producción de TIC para la formación. Barcelona: UOC.

Culturagalega (27 de decembro do 2004). Un grupo de mozos desenvolve sen ningún tipo de apoio un xogo de estratexia no noso idioma. http://culturagalega.gal/noticia.php?id=5490

DEV (20 de maio do 2014). Libro Blanco del Desarrollo Español de Videojuegos. http://www.dev.org.es/es/publicaciones/126-libro-bla nco-dev

Educación 3.0 (17 de xuño do 2015). ¿Cómo ven los docentes el futuro inmediato de la educación? http://www.educaciontrespuntocero.com/noticias/com o-ven-los-docentes-el-futuro-inmediato-de-la-educaci on/27152.html

Esnaola, G., De Ansó, B. e Untref (2014). Videojuegos y ludificación del aprendizaje. Tendencia clave en la innovación educativa. Revista Aprender para educar con Tecnología. 9, 4-7.

Fernández, M. (30 de xaneiro do 2012). Yoyago, un novo xogo galego de quebracabezas para iOS. http://codigocero.com/Yoyago-un-novo-xogo-galegode

Fernández, M. (2 de xaneiro do 2015). Os productores de videoxogos reivindican o seu recoñecemento como industria cultural. http://codigocero.com/Os-produtores-galegos-de

Fraga, H. (23 de marzo do 2010). Una tarde en Continental Games. $\mathrm{http} / / /$ blogocio.eleconomista.es/una-tarde-en-continen tal-games-no-25088/

Gfk (2012). aDeSe presenta el primer gran Estudio nacional sobre el uso del videojuego en la enseñanza: Videojuegos en las aulas [Informes]. http://www.aevi.org.es/docs/documentacion/estudiosy-analisis

Gros, B. (Coord.) (2004). Pantallas, juegos y educación. La alfabetización digital en la escuela. Bilbao: Desclée de Brouwer.

Gros, B. (Coord.) (2008). Videojuegos y aprendizaje. Barcelona: Grao.

Gros, B. (2012). Ponencia: Estrategias de aprendizaje basado en videojuegos en la formación del profesorado. Actas I Congreso Internacional de Videojuegos y Educación, 5-15. http://www.uv.es/ordvided/ACTAS/ACTAS\%20CIV E\%202012.pdf

Gros, B. (2014). Análisis de las prestaciones de los juegos digitales para la docencia universitaria. Revista Interuniversitaria de Formación del Profesorado. 79 (28.1), 115-128.

Lacasa, P. (2011). Los videojuegos. Aprender en mundos reales y virtuales. Madrid: Morata.
Marín, I., Penón, S. e Martínez, M. (2008). El placer de jugar. Aprende y diviértete jugando con tus hijos. Barcelona: CEAC.

Marqués, P. (2002). Evaluación y selección de software educativo.

http://diversidad.murciaeduca.es/tecnoneet/docs/2002/ 62002.pdf

Méndez, M.J. (2011). Videoxogos con selo galego. http://revista.mundo-r.com/gl/contido/videoxo gos-con-selo-galego

Montero, E. (Coord.). (2010). Aprendiendo con videojuegos. Jugar es pensar dos veces. Madrid: Narcea.

Ôfele, M.R. (2015). Juegos para la educación. Más allá del aula. Buenos Aires: CEPA.

Padilla, N.; Medina, N.; Paderewski, P.; Gutiérrez, F. e López, J. (2014). Diseñando Videojuegos para Aprender de Forma Divertida: En Busca del Equilibrio Perdido. http://gaia.fdi.ucm.es/sites/cosecivi14/es/papers/13.pd $\mathrm{f}$

Piaget, J. (1961): La formación del símbolo en el niño. México: Fondo de cultura económica.

Prensky, M. (2001). Digital Game-Based Learning. New York: McGraw Hill.

Prensky, M. (2006). Don't bother me mom - I'm learning! St. Paul: Paragon House.

Revuelta, F.I. e Esnaola, G.A. (2013). Videojuegos en redes sociales: perspectivas del edutainment y la Pedagogía lúdica en el aula. Barcelona: Laertes educación.

Rodríguez, C. (26 de febreiro do 2010). Creadores gallegos de videojuegos se abren camino a través del iPhone.

http://www.lavozdegalicia.es/tecnologia/2010/02/26/0 0031267173452723724240.htm

Rubio, M (2012). Retos y posibilidades de la introducción de videojuegos en el aula. Revista de estudios de juventud. 98, 118-134.

Suárez, O. (29 de xaneiro do 2010). Un videoxogo para o iPhone feito en Galicia. http://galego.lavozdegalicia.es/tecnologia/2010/01/29/ 00031264763652572726190.htm

Tonucci, F. (2004). La ciudad de los niños: un modo nuevo de pensar la ciudad. Madrid: Fund. Germán Sánchez Ruipérez.

Vygotsky, L.S. (1979): El desarrollo de los procesos psicológicos superiores. Barcelona: Crítica.

Xunta de Galicia (2005). Libro Branco do Sector Audiovisual en Galicia. http://www.observatorioaudiovisual.org/ver_esta_secc ion.asp?id=5 